\title{
NERUDA: EL RIZOMA DE RESIDENCIA Y EL CANTO
}

\section{Mario Rodríguez F.*}

\section{RESUMEN}

En el artículo se propone un análisis de las conexiones posibles de establecer entre Residencia en la tierra y Canto general. Para ello se abandonan las tesis que hablan de continuidad o de ruptura para trabajar con las fórmulas poéticas del entre, que rechazan los binarismos; el afuera, una línea mortal en que late sin embargo la vida; el pliegue, una forma de resistencia a la velocidad de la muerte, para determinar que los dos textos poéticos se conectan al modo de un rizoma.

Palabras claves: Entre, el afuera, el pliegue, rizoma.

AbStract

In this article we propose an analysis of some connections between Residence on Earth and Canto General (General Song). In order to do this, theses that speak of continuity or rupture are abandoned, to work instead with the poetic formulas of the inbetween, that reject the binary; the outside, a mortal line in which life nevertheless pulsates; the fold, a form of resistence to the velocity of death, to determine, finally that these two texts are connected in the form of a rhizome.

Keywords: Inbetween, outside, the fold, rhizome.

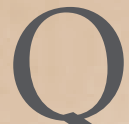

UIEN LEA el excelente trabajo de Federico Schopf, publicado en el volumen de Atenea inmediatamente anterior a éste, debe reconocer que está frente a un pensamiento crítico más avanzado que el de Loyola y Sicard, citados preferencialmente en la discusión sobre el tópico de la (inexistente) conversión poética nerudiana, propuesta por Alonso a propósito del poema "Reunión bajo las nuevas banderas".

${ }^{\star}$ Profesor de Literatura Chilena e Hispanoamericana Universidad de Concepción. E-mail: lgaravil@udec.cl 
Quiero avanzar, a mi vez, desde el punto en que finaliza el trabajo de Schopf hacia una propuesta más radicalizada sobre el tema en cuestión. Schopf sortea hábilmente los escollos de la dialéctica que paralizan (aparentamente) a Loyola y los afanes totalizantes que empujan a Sicard a una concepción teleológica de la obra nerudiana, para proponer que "por el contrario, las distinciones de varios niveles de significación y de disposición del sujeto 'diurno' y 'nocturno' -que hace Sicard- tendrían que conducir a que se exhiban las tensiones irresueltas o falsamente resueltas, entre el impulso de la representación totalizante y la apariencia fragmentada de los correlatos o entre la experiencia de la temporalidad como límite y su supuesta superación desde 'Reunión bajo las nuevas banderas' en adelante".

La inteligente proposición de Schopf de rescatar los varios niveles de significación y disposición del sujeto "diurno" y del "nocturno" (el primero afirma la prioridad del ser social y el segundo un "deber de ruptura" que deviene búsqueda metafísica) para privilegiar las "tensiones irresueltas", me permite dejar atrás las dicotomías, las oposiciones, los binarismos (diurnonocturno) y trabajar, experimentar, con el "espacio del medio", el que está allí donde lo diurno y lo nocturno se pliegan en una línea donde no se sabe dónde comienza uno y termina el otro. No se piense que el medio es una media, un espacio de neutra convivencia, ya que es más bien un sitio, en realidad, un "no lugar" por el que las cosas adquieren velocidad, como empujadas por la corriente de un río "que durando se destruye" al socavar las dos orillas.

Pliegue, media, no lugar, corriente de río, son los diversos nombres del espacio del "entre" (Deleuze) con el que deseo trabajar.

No voy a hablar de continuidad o ruptura del Canto general en relación a Residencia en la tierra. Voy a hablar de "flujos" naturales, de flujos personales, de flujos sociales, de flujos de vida y muerte que circulan por esos textos de Neruda, de sus velocidades y sus lentitudes (pliegues), y cómo se conectan, con qué hacen bloques o "agenciamientos" con el mundo natural y social y lo que permite todo ello. Huir de los binarismos, en primer término, y en segundo, de la noción de principio, fundamento, raíz.

Huir, entonces, del libro raíz y ver en estos dos textos de Neruda la forma del libro rizoma.

¿Por qué no el primero? Porque el libro raíz incita a ver la poesía de Neruda como representación del mundo y expresión de una subjetividad, cuando lo que hay son agenciamientos con el mundo:

esperé una hora quieta, aceché una hora inquieta recogí los herbarios del río.

Enfermo en Veracruz, recuerdo un día del Sur, mi tierra, un día de plata. 
A veces el viento del Sur resbala

sobre la sepultura de Lincoln trayendo

voces y briznas de ciudades y árboles.

Mar del Sur, mar océano,

mar, luna misteriosa

por Imperial guarnecida de robles.

por Chiloé a la sangre asegurada

y desde Magallanes hasta el límite

todo el silbido de la sal, toda la luna loca

y el estelar caballo desbocado del hielo.

Agenciamientos, bloques en el mundo natural, que muestran que la subjetividad no es patrimonio absoluto de la persona, sino que una ola, un día, el viento, una hora, pueden participar de ella.

Tal es el caso de aquellos versos citados que comienzan "Enfermo en Veracruz", donde el poeta se agencia una salud en el sur, con lo cual el paisaje deviene un agente activo, una forma de subjetivación positiva con la que entra en contacto el poeta. El otro tema vital que hay aquí es la memoria como salud, tópico central de muchos textos nerudianos.

El libro raíz ignora todo eso porque se propone como imagen del mundo, como su representación, y nada mejor que usar la forma del árbol o de la raíz como esa imagen, por las connotaciones sagradas, míticas (árbol del conocimiento, árbol de la vida, etc.), que ella tiene.

Raíz y árbol nunca dejan de desarrollar la ley de uno que deviene dos, que deviene cuatro, es decir la de la lógica binaria que da origen al pensamiento más razonable, más clásico, pero también el más caduco y manoseado. La mayor parte de la crítica ha interpretado así la poesía de Neruda, empezando por separar al poeta del político y continuando con múltiples oposiciones, es cierto que menos groseras que la primera, incluso sofisticadas (por ejemplo, una experiencia melancólica de la temporalidad, que como experiencia de fondo se opondría a un programa poético-político que pretende ignorarla), pero que nunca dejan de ser arborescentes, binarias.

La crítica siempre supone una fuerte unidad principal, que puede llamarse de varios modos, aunque siempre apunta a una raíz. "Fundamento" la llama Jaime Concha; "utopía totalizante", Sicard y aun Schopf cae en sus solicitaciones al hablar de "una experiencia profunda de la temporalidad".

La raíz pivotante le confiere el gran sentido a la obra nerudiana al que se subordinan todos los demás.

La forma raíz genera las categorías clásicas de la crítica nerudiana, como superación (Loyola), ciclos (Rodríguez Monegal), desarrollo (Concha), conversiones (Alonso). Implícita e explícita está la idea de que toda la poesía de Neruda se dirige a un punto culminante, a un punto de terminación, que varía según los enfoques críticos o ideológicos, pudiendo ser Residencia en 
la tierra (como pensaba Enrique Lihn), o Canto general o las 0 das el ementales, como celebraba Alone.

Yo veo la obra nerudiana como un rizoma, una multiplicidad en la que los diferentes libros se conectan unos a otros por tallos subterráneos/superficiales que terminan por configurar un gran bulbo. Mil mesetas poéticas, eso es la producción nerudiana. Cada meseta puede leerse por cualquier sitio y ponerse en relación con cualquiera otra. Tal vez con lo que afirmo no diga nada nuevo. La crítica ha recorrido el parentesco entre Residencia en la tierra y Canto general, por ejemplo, a propósito de la primera parte de Alturas de $M$ acchu Picchu, una suerte de balance de las subjetividades poéticas anteriores al encuentro con el monumento incásico. Aunque también debo decir que, en general, han destacado más las rupturas significativas entre libro y libro que las conexiones. De todas formas no se trata de encontrar nuevos parentescos, sino de entrar por el medio, hacer un intermezzo, hacer rizoma y no raíz, hacer entender ante todo que la poesía es desraizamiento, desterritorialización: "No hay raíces / para el hombre /: todo descansa apenas / en un temblor de lluvia". Ya es hora de dejar de territorializar a Neruda. Pronunciar un vade retro a los territorios políticos, sociales, americanistas, comprometidos y descomprometidos en los que se pretende aprisionarlo. Para ello, necesito repetir algunos conceptos fuertes, una suerte de eslóganes: En un libro no hay nada que entender, no hay nada que interpretar y sí mucho que experimentar, mucho que cuantificar.

Ya explicaré lo que ello significa, pero antes debo invitar(les) a rechazar la tripartición clásica que ha construido la crítica sobre la poesía nerudiana:

1. Un campo de realidad (el mundo)

2. Un campo de representación (el libro )

3. Un campo de subjetividad (el autor).

Nada de ello es muy importante porque es absolutamente predecible, como afirmar que ni en los momentos más metafísicos de la poesía de Neruda está ausente la realidad social o que el autor está marcado por experiencias primigenias, como su niñez en el sur, y para qué seguir, si al final nos vamos a encontrar con el siempre "sucio secretito": el del papá y la mamá, que están en el fondo de toda la literatura latinoamericana, especialmente la mamá.

No estoy de acuerdo con nada de lo anterior, porque comparto la idea que un libro es ante todo un agenciamiento $y$, añadiría, un agenciamiento con el afuera (Deleuze).

El afuera en Neruda es un límite -algo así como la fuerza de la muerte o una línea de "ballena enfurecida" (Melville) - frente al cual el sujeto se pliega.

El afuera es una zona de turbulencia que desata fuerzas incomprensibles, una zona de huracán. El afuera está en "la copa de sangre" que bebe el niño 
Neftalí y que desanuda todas las fuerzas del horror o en las terribles aguas verdes que chorrean interminables del ataúd podrido, cuando se desentierra el padre en el sombrío cementerio de Temuco. Ya no es el exterior que siempre se organiza en estratos, imágenes, en formas, como lo son, en relación a las experiencias anteriores, la lluvia del sur o la escena originaria con el padre.

Lo fundamental es cómo pliega ese afuera Neruda. Hay que cuantificar los pliegues como formas de resistencia al afuera, como lentificación de la terrible velocidad de la muerte, del "galope muerto" ("por eso en lo inmóvil, deteniéndose"). Hacer un pliegue -una detención- para respirar, hacer un pliegue para vivir, para resistir, para escribir: "desorden vasto / oceánico para mí que entro cantando como una espada entre indefensos".

Creo que el primer gran pliegue nerudiano es el del amor (en todas sus dimensiones, eróticas, sociales, sagradas, etc., entendido como un movimiento que pretende apartar al afuera de la muerte, del vacío. El pliegue del amor como un gran movimiento de vida, que lentifica la velocidad de la muerte.

Es lo que se busca en "Alturas de Macchu Picchu". Pliegue sobre pliegue el poema avanza hasta el gran sobrepliegue final, el amor solidario: ("Sube a nacer conmigo hermano"):

Amor, amor, no toques la frontera

ni adores la cabeza sumergida:

deja que el tiempo cumpla su estatura

en su salón de manantiales rotos...

y sube, flor a flor, por la espesura

pisando la serpiente despeñada

La fuerza del pliegue es aquí incontrarrestable presentándose como una línea flexible, migrante, que nunca se quiebra ni se segmentariza:

Porque el hombre es más ancho que el mar y que sus islas

Y hay que caer en él como en un pozo para salir del fondo

Distinta es la línea erótico-amorosa de los Veinte poemas de amor que tropieza porque es molar (se mueve pesadamente mediante figuras fijas como la de la amada, el crepúsculo, la ausencia) y sedentaria, porque si en "La canción desesperada" hay un anuncio de partida: "Es la hora de partir, oh abandonado, que podría ser considerada un rasgo de nomadismo, no es así porque sabemos que los nómadas nunca parten porque nunca hay llegada. Lo que hay es un movimiento "entre" la partida y la llegada. La partida es el engaño más seductor de los sedentarios -aquellos territorializados según fórmulas fijas: "abandonado como los muelles en el alba".

Puedo decir, en este punto, que si bien es cierto que las fuerzas de finitud han invadido en la poesía nerudiana la vida, el trabajo y el lenguaje, el poeta

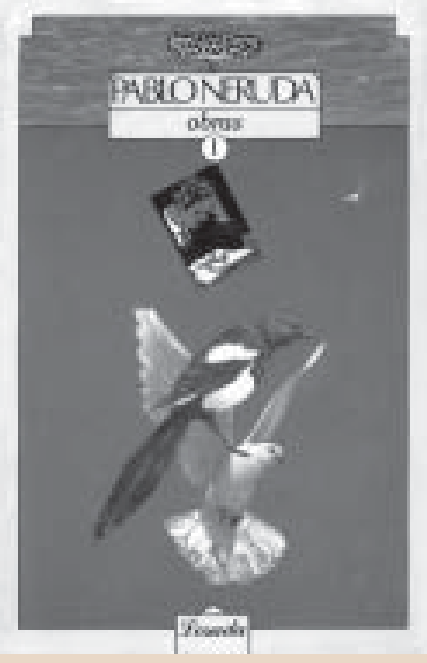




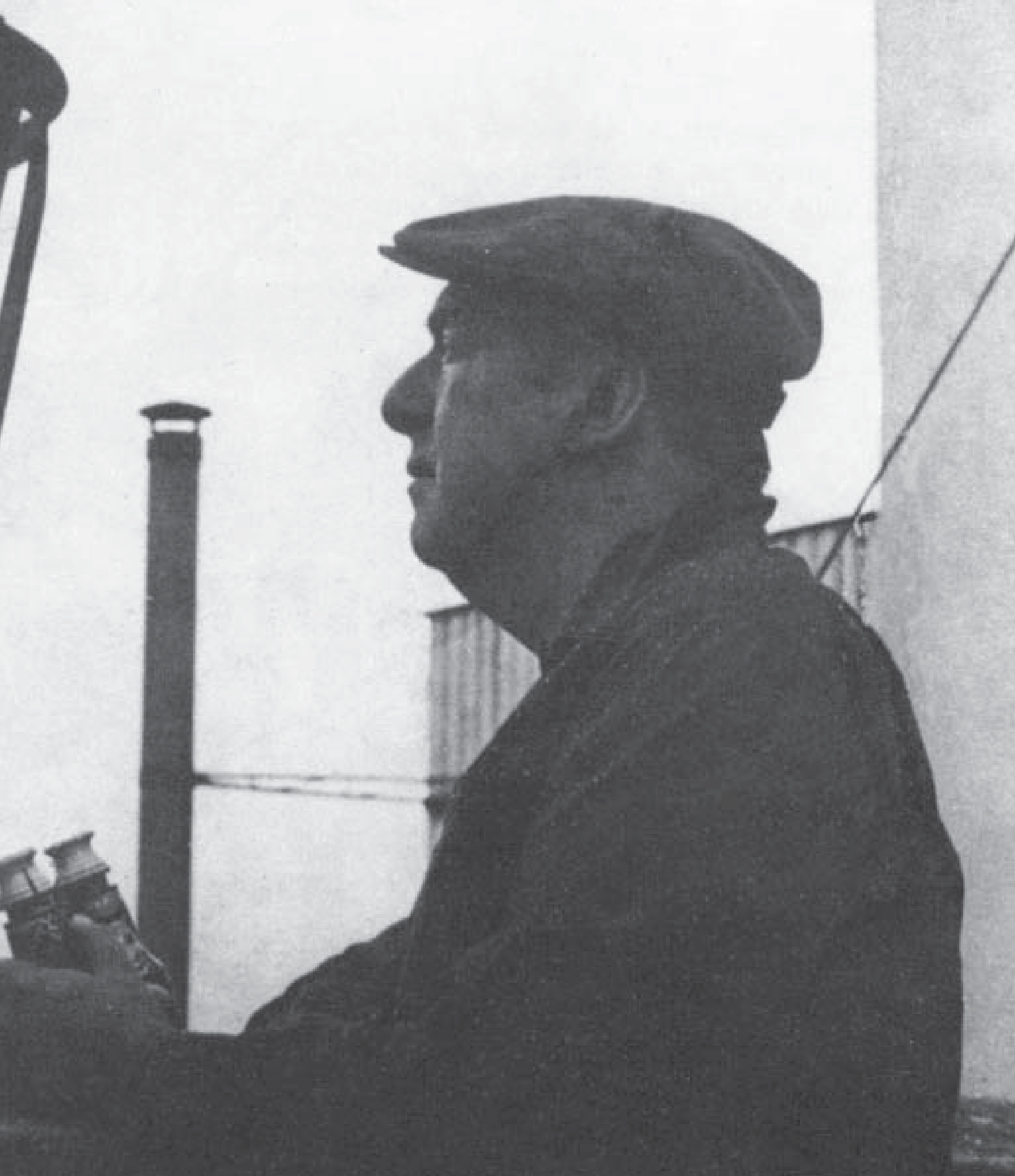


mediante el pliegue y el sobrepliegue (tan presente en Residencia) ha encontrado nudos de resistencia, líneas de fuga migrantes, nómadas y molares que le han permitido construir una subjetividad, un adentro del afuera (que no otra cosa es el pliegue). Esta relación consigo mismo en gran parte se presenta libre de sujeciones y controles (a pesar de lo que pudiera creerse). El poeta ha doblado las fuerzas del afuera para construir un espacio de libertad. Es cierto que se le imponen, o peor aún, se autoimpone identidades fijas, subjetivaciones provenientes de sistemas totalizantes en los que se organiza, se estratifica la exterioridad: ideologías estatizantes, humanismos escolares, territorializaciones mitificantes (el vate, el gran pedagogo, etc.), pero también es cierto que el dinamismo propio de la escritura nerudiana lucha contra esos controles con que se inviste el poder político o estético.

De aquí que si en el exterior (el espacio estratificado) el poeta se dedica a construir fuertes lazos ideológicos o imágenes canonizadas, como las ya mencionadas del vate y el "gran pedagogo", las fuerzas del afuera fracturan esos lugares, esas relaciones y avientan los diagramas, las figuras que dibujan las relaciones de poder.

Esa fuerza terrible que disloca hace inestables los diagramas, es también una fuerza de resistencia a la muerte o a las ideologías que quieren apoderarse de la vida. El afuera en Neruda tiene un componente de potente vitalismo que no se detiene en las especies ni en los medios, ni queda atrapado en tal o cual diagrama político.

Cuando ocurre lo último, estamos frente a los poemas más débiles de Canto general, que son aquellos en los que constituye algún diagrama ideológico que piensa la vida como algo a controlar. Así sucede en el Canto III "Los conquistadores" ("los carniceros desolaron las islas"), en el que el diagrama del antiimperialismo aprisiona toda otra posibilidad que no sea la negación violentamente negativa del invasor -no hay fugas, aunque existen devenires pero hacia al lado de las más manoseadas formas políticas, formas "molares" por excelencia: El asesino, o el mártir, el opresor o la víctima, los grandes binarismos que impiden la liberación de la vida en el hombre. Sólo cuando el poeta piensa contra los binarismos, contra las estratificaciones y se sitúa mágicamente en la 0, aquella letra que mora el "no-lugar", que está entre el opresor y oprimido, cuando se sitúa en esa "no-relación", en ese intersticio, nos comunica bellamente lo que puede hacer el hombre como conjunto de fuerzas que resisten. Y allí nacerán los más hermosos poemas de Canto general. En ellos Neruda es capaz de "liberar la vida" de donde permanece aprisionada. Tal ocurre en "Alturas de Macchu Picchu" y en "Que despierte el leñador".

En un libro no hay nada que interpretar, nada que entender y sí mucho que experimentar, mucho que cuantificar, repito la frase deleuzeana.

Entender estas afirmaciones no es fácil. Pero basta reemplazar el sistema de preguntas canónicas como: ¿Cuál es el sentido de Residencia en la tierra?, 
¿cómo expresa Neruda el amor al hombre en Canto general?, por otro sistema inédito de preguntas como: ¿Con qué fuerzas del afuera se conecta el poeta?, ¿qué conexiones establece para hacer pasar intensidades?, ¿cómo logra constituir un cuerpo sin órganos?

Me propongo analizar algunos poemas, como el inicial de Residencia en la tierra, "Galope muerto", para poner en acción estas preguntas:

Como cenizas, como mares poblándose, en la sumergida lentitud, en lo informe, o como se oyen desde el alto de los caminos cruzar las campanadas en cruz, teniendo ese sonido ya aparte del metal, confuso, pesado, haciéndose polvo en el mismo molino de las formas demasiado lejos, o recordadas o no vistas, y el perfume de las ciruelas que rodando a tierra se pudren en el tiempo, infinitamente verdes.

Aquello todo tan rápido, tan viviente, inmóvil sin embargo, como la polea loca en sí misma, esas ruedas de los motores, en fin.

Existiendo como las puntadas secas en las costuras del árbol, callado, por alrededor, de tal modo, mezclando todos los limbos sus colas.

Es que de dónde, por dónde, en qué orilla?

El rodeo constante, incierto, tan mudo, como las lilas alrededor del convento, o la llegada de la muerte a la lengua del buey que cae a tumbos, guardabajo, y cuyos cuernos quieren sonar.

Por eso, en lo inmóvil, deteniéndose, percibir entonces, como aleteo inmenso, encima, como abejas muertas o números, ay, lo que mi corazón pálido no puede abarcar, en multitudes, en lágrimas saliendo apenas, y esfuerzos humanos, tormenta, acciones negras descubiertas de repente como hielos, desorden vasto, oceánico, para mí que entro cantando, como con una espada entre indefensos.

Ahora bien, de qué está hecho ese surgir de palomas que hay entre la noche y el tiempo, como una barranca húmeda? Ese sonido ya tan largo que cae listando de piedras los caminos, más bien, cuando sólo una hora crece de improviso, extendiéndose sin tregua. 
Adentro del anillo del verano

una vez los grandes zapallos escuchan, estirando sus plantas conmovedoras, de eso, de lo que solicitándose mucho, de lo lleno, oscuros de pesadas gotas.

Desde el inicio del texto Neruda se conecta con flujos. Flujos marítimos, flujos sonoros, flujos de polvo, flujos vegetales, flujos de muerte (las ciruelas podridas, el buey que cae a tumbos guardabajo), flujos de vida (el verde infinito de los frutos). Neruda se conecta molecularmente con el mundo, con las fuerzas de finitud que lo componen y con las fuerzas que la resisten. Neruda, en general, en Residencia en la tierra es molecular, partícula que se desplaza entre los flujos: "Con mi razón apenas, con mis dedos / con lentas aguas lentas inundadas, / caigo al imperio de los nomeolvides"/. La realidad no está conformada por grandes figuras molares como la madre, el padre, la amada, la tierra natal, la madera, el ser, sino por flujos corporales que se desprenden de ellas: (la saliva, el sudor, el semen), flujos de muerte, de vida, flujos minerales, vegetales, flujos de agua sombría, flujos de tiempo ("El fantasma del buque de carga"), flujos sonoros, flujos silenciosos, flujos con velocidades fantásticas (los del afuera) o lentitudes semidormidas. La velocidad del flujo de la muerte es espantosa cuando llega a la lengua del buey o es loca la velocidad de la vida cuando gira sobre sí misma, pero es lentísima cuando hace un pliegue para llegar a las grandes plantas: "estirando sus plantas conmovedoras / de eso, de lo que solicitándose mucho, / de lo lleno, oscuras de pesada gotas".

Lo que importa, luego, es cuantificar las velocidades: cuántos flujos veloces, cuántos flujos lentos, cuántas detenciones y aceleraciones, cuántas las fuerzas de sus intensidades. Por ejemplo, las velocidades de los flujos temporales son muy rápidas porque están unidas a la terrible velocidad de la muerte: "como el río que durando se destruye". Veloces son, también, los flujos del vino porque están emparentados con la misma huida: "y el vino huye por las carreteras /... buscando pozos, túneles, hormigas, / bocas de tristes muertos".

Por el contrario, los flujos de amor-vida se lentifican en un soblepliegue de descanso y protección:

Los días acechando cruzan en sigilo pero caen adentro de tu voz de luz Oh dueña del amor, en tu descanso fundé mi sueño, mi actitud callada

Para que todo circule, el yo estratificado, el gran yo poético, debe renunciar a su organización molar, ciertamente autoritaria en el sentido que todo llega al yo para depositarse en sus capas estratificadas. El yo deviene lo que 
quería Artaud "cuerpo sin órganos", única disposición que permite la circulación de las velocidades e intensidades de los flujos: "mezclando todos los limbos sus colas".

Es particularmente expresiva esta forma del yo, "cuerpo sin órganos", en relación a la constitución del yo en Canto general. Un rotundo verso del poema pórtico: "Amor América": "Yo estoy aquí para contar la historia" nos indica que en varios puntos del texto hay una subjetivación contraria a la que circula por Residencia en la tierra, molecular y desestratificada. Se edifica en estos puntos un yo molar, centralizador, autoritario que asume plenos poderes sobre la verdad de la historia.

El yo de Canto general, puedo decir, se autoproclama inserto en un diagrama de poder. Ello significa constituirse como un polo de fuerza en una relación con otras fuerzas que pugnan por establecer la mentira. Este binarismo peligroso y estéril, yo digo la verdad de la historia contra los que la han falseado, pudo transformar el Canto en un texto maniqueo y esquemático, organizado en grandes bloques molares: héroes y antihéroes, oprimidos y opresores, libertadores y esclavizadores, etc. Peligro enfatizado por la inclinación del yo hacia esta figura del vate, del poeta oracular.

Sin embargo, las fuerzas del "afuera" que circulan en toda la poesía nerudiana con la potencia de vida y muerte propia de ese "afuera", impiden la estratificación, el binarismo convencional, manoseado y paralizante, tan amado, sin embargo, por muchos porque es tranquilizador y políticamente correcto.

Bella y milagrosamente la poesía renace de las ruinas de los binarismos. El mismo poema citado "Amor América" contiene una admirable estrofa:

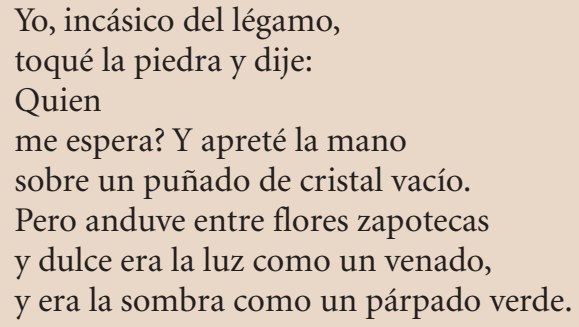

El yo autoritario, dominante y dueño de la verdad ha devenido indio, figura minoritaria totalmente opuesta a los rasgos reseñados del yo, y aún más, indio solitario enfrentado al vacío, indio sin territorio, o mejor dicho, habitante de un territorio mudo, sin signos que puedan hablarle.

Pero de esta territorialización marcada por la ausencia y el vacío, el sujeto mediante un agenciamiento con la flor, la luz y la sombra avanza hacia un nuevo territorio, una reterritorialización profundamente positiva que le permite descubrir que el "reino muerto vive todavía".

Podría decir que la sugestión y belleza de Canto general no proviene de 
territorializaciones autoritarias o ideológicas, sino de sus desterritorializaciones, verdaderas "líneas de fuga" que habiéndose iniciado en Veinte poe mas de amor y una canción desesperada ("todo en ti fue naufragio") continúan en toda la obra nerudiana destruyendo los binarismos para constituir un espacio del "entre" en el que las fuerzas de la vida se confunden con las fuerzas de la muerte en un apretado nudo ("ahora bien, de qué está hecho ese surgir de palomas / que hay entre la noche y el tiempo, como una barranca húmeda?") plegado sobre sí mismo tan fuertemente que pareciera impedir todo despliegue. Sin embargo, el vuelo de la paloma, la fuerza de la vida, es tan poderosa que es capaz en un instante feliz de abrir el pliegue para que suenen y resuenen las campanas de la vida:

\section{$\mathrm{Y}$ ardamos y callemos y campanas.}

Digo que es un instante, porque lo que predomina es el pliegue donde la vida yace en los brazos de la muerte o viceversa. Pero la poesía, como piensa Paz, es la "consagración del instante", y son esos momentos en los que la vida se remonta para hacer agenciamientos con las piedras, los ríos, el mar o lo más puro del hombre devenido hermano, donde la poesía de Neruda alcanza toda su potencia y hermosura.

Afirmo, entonces, que Neruda para vivir, respirar, debe plegar las asfixiantes fuerzas del afuera, en tanto que para escribir debe liberar -desplegar- lo positivo (la vida) que late en el pliegue expresado genialmente en el verso:

Ceniza llena de apagadas almas.

En el flujo de destrucción y muerte (la ceniza) está latiendo el impulso de la vida pronto a encenderse ("apagadas almas"), en despliegue ígneo.

En muchos poemas, especialmente de Canto general, el triunfo de la vida es explícito, como en "Disposiciones" donde el poeta pide ser enterrado en Isla Negra frente al mar, para ser arrastrado "hacia abajo en las lluvias que el salvaje viento del mar combate y desmenuza"; para subterráneamente conectarse con "la primavera profunda que renace".

En otros, particularmente en los de Residencia en la tierra, el despliegue de la vida es más secreto, más difícil de captar. Así sucede en "Alianza (sonata)", donde el vuelo de palomas (el flujo de la vida) es ahora el deslumbrar de mariposas: "En lo alto de las manos el deslumbrar de mariposas", o el "rojo caballo, desnudo, sin herraduras y radiante". Plegado en su interiorexterior el poeta guarda " un aceite vivo" o una "luz de amapola" que muerde con delirio. El pliegue de la vida da una línea de fuga que resiste con vigor y hermosura a la muerte, a "la muerte vestida de escoba" lamiendo el suelo para juntar difuntos, o a "la lengua de la muerte" buscando muertos o a la "aguja de la muerte" buscando hilo. 
Pero existe aquí un punto importante, ya marcado, y que volvemos a remarcar. La fuga sólo es posible cuando el poeta abandona el yo centralizador que asume la figura del vate, del oráculo o del profeta. Cuando Neruda deviene molécula, como en "Entrada a la madera", o ser anónimo "sin nombre ni estado", como en "Vals", o semilla "como una vieja lágrima enterrada" o voz por la que hablan los ríos ("Bío-Bío") o viento en "Que despierte el leñador", su poesía se asemeja a las grandes cumbres de la Cordillera de los Andes. Al contrario, cuando deviene hacia el otro lado, el opuesto al devenir minoritario que he descrito, su poesía cae a las hondonadas de los maniqueísmos, donde estérilmente clama el Hombre con mayúscula, ese hombre que ha engendrado el odio por incapacidad de entender al otro, sea el traidor "la rata de palacio", "los pijes, granfinos, pitucos", "las pálidas niñas principales", los "gidistas", los "rilkistas", los "falsos brujos existenciales".

Muchos creen ver en esta poesía de recriminaciones, denuncias, vituperios apasionados, una fuerza política entrañable a toda la poesía nerudiana que la mueve por entero. El problema no es político sino de devenires. "Pensamos demasiado en términos de historia personal o individual" (Deleuze 1980:6), cuando los devenires son, en realidad, asunto de geografía, es decir, de direcciones, de líneas de salidas y entradas. No se trata, en este sentido, de hacer calcos, sino mapas. Hacer calcos con Neruda es partir de un principio, del uno generador del dos: el fundamento, el principio totalizador, el compromiso social. Cada uno de estos principios engendra su contrario para hacer avanzar así la poesía nerudiana: héroes y antihéroes, libertadores y opresores, etc. Hay, sin embargo, un devenir revolucionario que no se confunde con el futuro de la revolución y que no pasa exclusivamente por los militantes.

Porque devenir no es imitar ni adaptarse a un modelo, aunque sea el más prestigioso (el de la justicia) o el más amado (el de la libertad) porque los modelos son siempre autoritarios, molares, formas del poder disciplinario.

Ese es el problema básico de muchos poemas de Canto general y de la totalidad de Las uvas y el viento.

No se trata de una "crítica reaccionaria", sino de mostrar una debilidad de la poesía nerudiana que se produce cuando el poeta deviene figura "molar", revolucionario que se confunde con la revolución, voz de los sin voz, vate dueño de la verdad. No hay aquí salidas ni entradas -mapa- sino calcos, y duros, de una idea del hombre como figura dominante, autoritaria -iqué vergüenza de ser ese hombre!-. Pero hay una fuga, o varias, a esa vergüenza. La más bella y que me sigue conmoviendo es la que se produce en el Canto VI del poema "Que despierte el leñador":

Que nadie piense en mí.

Pensemos en toda la tierra, golpeando con amor en la mesa. 
No quiero que vuelva la sangre

a empapar el pan, los frijoles,

la música; quiero que venga

conmigo, el minero, la niña,

el abogado, el marinero

el fabricante de muñecas

que entremos al cine y salgamos

a beber el vino más rojo.

Yo no vengo a resolver nada

Yo vine aquí para cantar

y para que cantes conmigo.

Bastan dos versos para entender la fuerza de la línea de fuga como resistencia a la exclusión del otro, del "enemigo", "quiero que venga conmigo" ... "el abogado" ... "el fabricante de muñecas". La que en otros pasajes de Canto general es una figura torva, el abogado, aquí se incluye en la totalidad fecunda que acompaña al poeta.

El verso "Yo no vengo a resolver nada" marca este mismo devenir minoritario del sujeto, opuesto rotundamente al devenir mayoritario que expuso el ya citado verso de "Amor América": "yo estoy aquí para contar la historia".

Rescato versos bellísimos de Canto general presentes aún en poemas de gran contingencia política como "Coral de año nuevo para la patria en tinieblas", en que llama a González Videla "perro mentiroso", "piojo maligno", $y$ en que, sin embargo, el poeta es capaz de escribir hermosos versos en que hace agenciamientos profundos con la "nave" de la patria y su perfume: Soy parte tuya: círculo / secreto de madera sorprendido en tus árboles, / crecimiento callado como tu suave azufre, / estentórea ceniza de tu alma subterránea".

Aquí funciona una lengua menor dentro de esa lengua mayor que aparece y reaparece en Canto general, lengua mayor porque se afirma en el poder de las constantes, en un metro-patrón mayoritario: un hombre blanco-macho-adulto-urbano hablando una lengua estándar, al que habría que añadir el metro-patrón del marxismo que "ha traducido casi siempre la hegemonía desde el punto de vista del obrero nacional cualificado, macho y de más de treinta y cinco años" (citado por Deleuze y Guattari, 1997).

Negando la homogeneidad de esta lengua mayor, aparece la menor. No se trata de dos lenguas, sino de un uso distinto de una misma lengua, una suerte de bilingüismo en el interior de nuestra propia lengua. La minoridad no es una cualificación, sino un poner en un estado de variación continua la lengua, consiguiendo una desterritorialización de ella. La desterritorialización se produce en los versos citados a través del contrasentido: el poeta es al mismo tiempo crecimiento callado y estentórea ceniza. Muchas imágenes 
de Canto general y casi todas de Residencia en la tierra están construidas mediante el contrasentido (" $y$ las ciruelas que se pudren en el tiempo infinitamente verdes"); puedo decir que casi no hay contrasentido que sea bello. Proust afirmó: "Los libros más bellos están escritos en una especie de lengua extranjera". Ser un extranjero en la propia lengua significa hablar con contrasentidos que son, como dije, de gran belleza, y ahora añado, siempre que no conciernan a interpretaciones, sino a un uso del libro como una multiplicación, un rizoma, que se instala en el espacio del "entre", aquel que aparece cobijado en el contrasentido del título del poema inicial de la primera Residencia: "Galope muerto". Movimiento y anulación inmediata de él, vida que conlleva la muerte. Hay algo aquí como una suerte de tartamudeo de la lengua que salta sobre los binarismos, que los desterritorializa.

La lengua menor, la lengua tartamuda, desterritorializada, abre las palabras y las cosas por el medio liberando fuerzas que proceden del afuera y que sólo existen en estado de agitación, de mezcolanza. Línea terrible de muerte, como dije, pero también de vida, como en "Galope muerto" o en ese hermosísimo poema "Barcarola".

Si solamente me tocaras el corazón,

si solamente pusieras tu boca en mi corazón,

tu fina boca, tus dientes,

si pusieras tu lengua como una flecha roja

allí donde mi corazón polvoriento golpea,

si soplaras en mi corazón, cerca del mar, llorando,

sonaría con un ruido oscuro, con sonido de ruedas de tren con sueño,

como aguas vacilantes,

como el otoño en hojas,

como sangre,

con un ruido de llamas húmedas quemando el cielo,

sonando como sueños o ramas o lluvias,

o bocinas de puerto triste,

si tú soplaras en mi corazón cerca del mar,

como un fantasma blanco,

al borde de la espuma,

en mitad del viento,

como un fantasma desencadenado, a la orilla del mar, llorando.

Como ausencia extendida, como campana súbita,

el mar reparte el sonido del corazón,

lloviendo, atardeciendo, en una costa sola:

la noche cae sin duda,

y su lúgubre azul del estandarte en naufragio

se puebla de planetas de plata enronquecida. 
Y suena el corazón como un caracol agrio, llama, oh mar, oh lamento, oh derretido espanto esparcido en desgracias y olas desvencijadas: de lo sonoro el mar acusa sus sombras recostadas, sus amapolas verdes (...)

El texto está construido sobre la imagen del corazón-caracol (como ya lo dijo Alonso) y la mujer fantasma que podría soplar en él. Si lo hiciera el corazón sonaría como la muerte y "llamaría como un tubo lleno de viento o llanto" o "una botella echando espanto a borbotones".

Por el intersticio que deja la no coincidencia entre el ver y hablar (sobre el corazón-caracol) se precipitan las fuerzas de la muerte, como una tempestad desatada por el girar de las alas negras del mar, pero pasan también por la brecha las fuerzas de la vida, del erotismo, presente en la fina boca, los dientes, la lengua como una flecha roja de esa mujer, al mismo tiempo, fantasma y presencia viva.

La imagen tradicional (presente en Darío, por ejemplo, que escribe "el caracol la forma tiene de un corazón”) está construida sobre la analogía, la coincidencia o semejanza entre la forma del corazón y la del caracol marino. Neruda rompe esa analogía transformando al corazón en un "maléfico pito", en un tubo lleno de llanto o en una botella que echa espanto o borbotones.

En Darío las palabras y las cosas coinciden a través de la escritura de la semejanza. En Neruda la analogía se rompe y lo visible ya no coincide con lo enunciable. Esa falta de coincidencia es lo que llamo intersticio, brecha, y digo por allí pasan las fuerzas del afuera con su doble cortejo de muerte y de profundo erotismo: "si pusieras tu lengua como una flecha roja".

Resulta, finalmente, que el espacio del "entre" es el espacio poético por excelencia en cuanto lo entendamos en su fascinante contrasentido: un "no lugar", una "no relación". En ese no lugar, que es el de la gran poesía, el de la escrita en una lengua menor, el poeta puede solicitar, rogar, por un vínculo humano admirable en su espléndida materialidad:

Si solamente me tocaras el corazón, si solamente pusieras tu boca en mi corazón.

La boca que sopla en el corazón-caracol no es una cualquiera, ni es neutra. Es una boca llena de ardor que besa con la lengua plena de flujos vitales. Darío en su poema "Caracol" sólo lleva a sus labios el caracol sin queintervenga ni la lengua, ni los dientes, para "suscitar el eco de las dianas marinas".

La escritura de la semejanza hace apacible al mundo, lo muestra como un teatro lleno de correspondencias y acordes ("las dianas marinas"). La escritura del entre destituye las coincidencias, derriba la ontología y hace 
trizas el fundamento del ser, anula cualquier comienzo o fin porque siempre tiene un medio por el que crece y desborda. En el entre se realizan las más hermosas líneas de fuga de la poesía nerudiana, las líneas que resisten al poder y a la ideología. El entre es la fisura por la que penetran las fuerzas del afuera y se crea el pensamiento transgresor. Si hay un "pensamiento poético" en Neruda no es un pensamiento totalizador porque el entre no soporta las totalizaciones, el entre abandona los estratos y el pensamiento estatal revolucionario o conservador. El prodigio de Canto general en su capacidad de desestratificarse, de abandonar los binarismo, de rechazar el pensamiento estatal y sus puntos culminantes (como el estalinismo), que no son los que precisamente perdurarán en la emoción de miles de lectores.

No pensemos a Canto general como libro raíz. Pensémoslo como un rizoma que constituye una meseta, una región de intensidades que vibra sobre sí misma, sin una orientación a un punto culminante o hacia un fin exterior, aunque una lectura desatenta o el mismo poeta pareciera indicarlo así.

Dije, Mil mesetas poéticas es la obra de Neruda, y en cada una de ellas vibra la misma intensidad expresada en "Barcarola".

Si solamente me tocaras el corazón.

Agenciamiento del deseo, de un sujeto que se resiste a ser dominado por la soledad, la muerte y la ausencia del otro. Vibrando la meseta para conectarse con flujos materiales, sociales y semióticos.

El agenciamiento significa conectar la separación de la tripartición canónica -de la que hablé- entre un campo de realidad, el mundo, un campo de representación, el libro y un campo de subjetividad, el autor. Los agenciamientos ponen en conexión ciertas multiplicidades pertenecientes a cada uno de esos órdenes. Ello significa rechazar la idea de las continuaciones, cambios u oposiciones. Residencia en la tierra no se continúa ni se opone a Canto general; lo que hace, como escribí, es conectarse por tallos subterráneos o superficiales hasta formar con él un rizoma.

La conexión se hace a través de una fisura, de un pliegue, por el que pasan las fuerzas de la vida y de la muerte ("cenizas llenas de pagadas almas"), con todos sus bellos contrasentidos que le confieren a la poesía la fascinación que produce estar leyendo una lengua extranjera dentro de la propia lengua:

Como cenizas, como mares poblándose en la sumergida lentitud, en lo informe. 
Alone (Hernán Díaz Arrieta). 1955. "Muerte y transfiguración de Pablo Neruda". Diario El Mercurio. 30.01. Santiago.

Alonso, Amado. 1966. Poesía y estilo de Pablo N eruda. Buenos Aires: Editorial Sudamericana. Tercera edición.

Deleuze, Gilles / Claire Parnet. 1980. Diálogos. Valencia: Pre-Textos.

Deleuze, Gilles y Félix Guattari. 1997. M il mesetas. Barcelona: Pre-Textos.

Loyola, Hernán. 1967. Ser y morir en Pablo Neruda. Santiago: Editorial Santiago.

Neruda, Pablo. 1993. O bras completas. Buenos Aires: Editorial Losada.

Schopf, Federico. 2003. "El problema de la conversión poética en la obra de Pablo Neruda”, Atenea No 488, segundo semestre, pp. 47-48.

Sicard, Alain. 1982. El pensamiento poético dePablo Neruda. Madrid: Editorial Gredos.

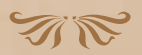

